ased, and the arch of this vessel had undergone dilatation a about twice its normal calibre. Both the aortic and aitral valves were puckered sufficiently to allow of reguritation.

\section{A CASE OF TRAUMATIC DELIRIUM; RECOVERY.} (Under the care of Mr. SAvORY.)

In the following example the disease which has been rariously designated as "traumatic delirium," and " prosration with excitement," supervened with remarkable selerity on the injury, and, by yielding with almost equal peed to a single dose of morphia, confirmed the established ractice of treatment by opiates.

George D—, forty-two years of age, was admitted in a state of unconsciousness produced by the fall of a heavy veam of wood on his chest. Very shortly afterwards he assed into a state of delirium. The subcutaneous injection if half-a-grain of morphia was followed in a few minutes by quiet sleep. In a few hours he resumed consciousness, and complained of great pain in the chest. Though conscious, he remained dull and forgetful ; when told to hold a thermometer in his mouth, he expressed compliance, but in a few seconds allowed it to fall. On the third day, the aplication of a linseed-meal poultice to the abdomen was followed by an improvement in his condition. Half an ounce of castor oil, administered on the fifth day, cleared his tongue of a thick brown fur, and effected a further general improvement. On the fourteenth day he was discharged, well.

\section{GUY'S HOSPITAL.}

\section{WARTY GROWTHS IN THE LARYNX; REMOVAL BY} BRONCHOTOMY ; RECOVERY.

(Under the cars of Mr. Thomas Bryant.)

We are favoured with the notes of the following two cases by Mr. R. S. Mutch.

A. T- , a healthy-looking boy three years of age, was admitted with complete loss of voice. On examination, some slight swelling, more appreciable to the touch than to the sight, was observed over the external surface of the larynx. Neither the skin nor the adjoining lymphatics were affected. The swelling was hard and immovable.

According to his mother's observation, he had first become hoarse about sixteen months previously, and for about fourteen months had been quite voiceless. His health had always been good. There was no family history as regarded tumours, but abundant evidence of phthisis. 'The loss of voice was attributed to his having kicked off the bedelothes and lain for some time as cold as a "piece of ice."

Having come to the opinion that the child's larynx was occupied by adrentitious growths, Mr. Bryant made first an opening in the median line sufficient to admit of the introduction of a tube into the trachea, and then laid the larynx open by an incision from within and below. Considerable hæmorrhage occurred, but was arrested by torsion. Innumerable warty growths, springing from the epiglottis and rima, were then removed with dressing-forceps and the handle of a scalpel. The interior of the larynx was then sponged with tincture of perchloride of iron, the tube tied in position, and the incision above it closed with sutures. During the operation the complexion became livid and the respiration slow, but on its completion these symptoms rapidly subsided. On being removed to the ward, the patient was placed near a fire, a screen was placed round the bed, and a bucket of steaming water kept constantly at its side. On the fifth day the tube was removed, and a good deal of discharge issued from the opening; he was found able to express himself in a whisper. On the twenty-third day he was discharged; the wound had closed, the respiration was carried on without difficulty, and the voice had undergone a great improvement. He was seen again sixty days after the operation; the voice had become much more natural, and there existed not the slightest obstruction to the respiration.

REMOVAL OF CONGENITAL FIBRO-CELLULAR TUMOUR IN THE BUTTOCK.

(By Mr. BRYANT.)

John B-, aged fifty, stated that from birth he had had a tumour on the right buttock, near the median line.
Until within two or three years it had neither undergone increase nor caused inconvenience. About two months before admission it began to increase rapidly and became red, hot, and painful; shortly afterwards it broke and discharged matter with blood. Still it continued to grow rapidly larger ; it continued also to exude blood and matter, but only gave pain when subjected to violence of some kind. There was found to be on the right buttock a tumour eleven inches and three quarters in circumference at the base, and eight inches diametrically over the summit. The skin was somewhat red and thickened. Its summit was flattened, and presented a dark, elevated patch about two inches and a half in diameter, with undermined, but not everted, edges; it emitted fetid sanguineous matter. The whole was movable on the solid parts beneath; but an indurated condition of the subcutaneous tissue extended to a distance of about an inch from its base. It did not encroach beyond the median line; gentle manipulation produced no pain, and its bulk did not in the least degree interfere with the movements of the leg.

The tumour was excised by means of a circular incision; the bleeding was slight, and was easily controlled by torsion. The patient made an uninterrupted and complete recovery.

\section{HOSPITAL FOR SICK CHILDREN.}

\section{A DRESS-HOOK LODGED IN THE LARYNX; REMOVAL BY} BRONCHOTOMY; DEATH ON THE SEVENTH DAY.

(Under the care of Dr. GeE.)

Fon the notes of the following case we are indebted to Mr. H. T. Butlin, the medical registrar.

Five days before admission, the patient, Lily A. A- a healthy child of eighteen months, was pretending, in her play, to drink out of a jam-pot which her mother, a dressmaker, positively asserted to have been empty. Suddenly she uttered a scream, and appeared to be choking. From that time her breathing became difficult; she had occasional fits of choking, and her voice remained hoarse. She could lie down, had been sick the night before admission, but had not brought up any blood. On the day following the first appearance of these symptoms she was examined at one of the general hospitals; but she was not at the time suffering from dyspnca, only a few bronchial râles were to be heard, and she was prescribed for accordingly.

On admission she had lost something of the healthy appearance said to be habitual to her; she sat up in the nurse's arms breathing loudly with ex- and in-spiratory dyspnœea, and with dilated nostrils. There was retraction of the episternal and epigastric regions. The face was much drawn, and dusky; the lips were of fair colour. She had a cool skin, a clean tongue, and a throat of natural appearance. The two sides of the chest were symmetrically affected, while the percussion-note was universally good.

Notwithstanding the assurance of the mother that the jam-pot had been quite empty, the symptoms were so suggestive that Mr. Sankey, the house-surgeon, at the request of Dr. Gee, at once proceeded to perform tracheotomy. Having opened the trachea from the thyroid body upwards, the operator perceived a body which, after clearing away a quantity of thick, puriform matter, he was able to seize with forceps, but not to move on account of its firm attachment. $\mathrm{He}$ therefore prolonged his incision upwards through the cricoid cartilage, and found that an ordinary dress-hook was attached to one of the vocal cords. A hook of this description, as is well known, is provided on either side of the base with an almost circular loop formed by the curving outwards and upwards to the side of the stem of the respective ends of the reduplicated wire, and by means of which it is sewn on to the dress. So firmly were the tissues gripped between one of these recurved ends of the wire and the stem of the hook, that it was found necessary to divide them with the knife. The child was sick during the operation, and looked pale and ill for some time afterwards.

About three hours after the operation, the breathing being somewbat laboured, a tube was passed into the tracheal opening with manifest advantage. In the evening the patient vomited several times, but afterwards passed a good night. On the following (second) day the tube was removed at mid-day. She breathed fairly well, inspiring 
through the wound, and expiring through the mouth and nose. With the exception of the edges of the wound being red and presenting a pouting appearance on the third day, and the discharge of a good deal of thick puriform matter, she continued to make favourable progress until the sixth day, when the tube bad to be reinserted on account of difficulty of breathing. 'This measure gave relief for a time, but in a few hours the difficulty became steadily greater, and neither the introduction nor the removal of the tube, nor any other proceeding, afforded any relief. After suffering great dyspncea, chiefly expiratory, she died on the seventh morning.

At the post-mortem examination the body was found to be well nourished. The wound gaped and looked unhealtny; it emitted thick, brown, frothy matter. The epiglottis was slightly injected; both vocal cords were much congested; in the centre of the right one was found the notch caused by the removal of the hook. The trachen contained a considerable quantity of thick semi-purulent fluid; its mucous membrane was congested. Both lungs were emphysematous anteriorly, and œdematous throughout. The bronchial tubes contained a great quantity of thick tenacious matter, and bore evidence of congestion. There was no collapse, and there were no traces of pneumonia.

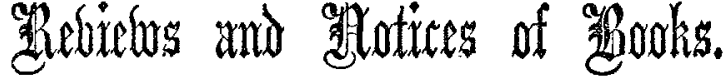

A Manual of the Laws Affecting Medical Men. By RoBerT

George Glenn, LL.B., Barrister-at-Law. 8vo, pp. 460. London: J. \& A. Churchill.

In preparing this manual, Mr. Glenn has executed a difficult task in a very satisfactory manner, and has conferred a great obligation upon the profession. Individual practitioners find, every now and then, that they require to be enlightened upon some legal point connected with their calling; but very few are aware of the number of possible points of friction between the two black gracesLaw and Physic. It is our lot to be frequently appealed to for information upon these points; and scarcely a week passes in which we have not felt difficulties, many of which Mr. Glenn's work will remove. We say many of which, because we do not expect it to reach perfection in a single edition, and its shortcomings can only be made fully manifest by experience. For example, we can find in it no reference to a question that has recently come into prominence-namely, the right of a coroner to order a medical man to make a personal examination of a woman who was suspected of having given birth to a child. In a wellknown instance, a coroner issued such an order, and the medical man to whom it was addressed considered it valid, and endeavoured to carry it into effect, with what result it is unnecessary now to repeat. We believe the coroner was altogether exceeding his authority, and that the medical man would have been liable to punishment for assault if he had succeeded in doing what was required of him. As in this instance, cases not provided for must every now and then crop up; but, upon the whole, we think Mr. Glenn's treatise remarkably accurate and complete, and deserving of high commendation.

The book opens with a preliminary chapter containing some quaint lore abont the early history of the profession, the bearing of which upon the main subject is not obvious, although the matter is curious and entertaining. The second chapter deals with Registration; the third with the Licensing and Qualifying Bodies (we trust this may soon require to be entirely rewritten); the fourth with the Registration of Chemists and Druggists; the fifth with Offices held by Medical Men; the sixth with their Rights and Privileges; the seventh with their Duties and Obligations; and the eighth with the Laws affecting them in their relations with Partners, Assistants, and Apprentices. An appendix contains an essay on Medical Etiquette by Dr. Alfred Carpenter, some instructions for the execution and attestation of wills, and a set of forms of deeds, agreements, indentures, and contracts of various kinds.

The essay by Dr. Carpenter occupies thirty pages, and deals, in a very sensible and pleasant manner, with the chief points of medical etiquette, explaining the principles on which certain received customs are founded, and the manner in which their observance contributes to the common good. In the indicated space there are of course many points that are only just touched; but the essay, as a whole, is very valuable, and well calculated to explain to nonprofessional people the grounds of conduct which they cannot always understand. We do not agree with Dr. Carpenter in every word that he advances, but we concur with him thoroughly in the main, and we feel that the subject of which he treats could have had no more worthy or more conscientious expositor. The book, taken altogether, is eminently clear and practical, and is calculated to be of great utility.

Sull' Ultimo Stadio di Colera Asiatico-o Stadio di Morte apparente dei Colerosi.

On the Last Stage of Asiatic Cholera-viz., the Stage of apparent Death of Cholera Patients. An Essay by Professor PacrNi. Reprinted from the Imparziale. Florence, 1871.

Professor Pacini is not only known as one of the most profound anatomists of Italy, but his experiments and discoveries in physiology have given him a world-wide reputation. Not content with studying the laws which govern the functions of the frame, he has cultivated pathology, and has, especially as regards cholera, published several pamphlets $(1855,1865-66)$, in which the subject is treated physiologically and mathematically.

Dr. Pacini thinks he has discovered the ferment or fungus of cholera; and upon the idea that the loss of epithelium of the intestinal mucous membrane is due to the action of this ferment, his theory is founded. The latter has not been unconditionally received either in Italy or in other countries; but it is allowed by many that the Professor is, probably, not very far from the truth.

The present pamphlet, however, treats principally of the apparent death of cholera patients, and is well worthy of attention, especially at the present time. A short analysis of the Professor's views on cholera will be necessary for the due appreciation of the merits of the present essay.

In a former work ("Sulla Causa Specifica del Colera Asiatico, \&c.; Firenze, 1863"), Dr. Pacini tried to prove that cholera was excited by the presence of a fungus; and asserted that he had discovered the supposed choleraic ferment which destroys the absorbing epithelium of the gastro-enteric mucous membrane, and transforms a portion of its absorbing surface into a transuding surface. From the latter arises the flux which, at the outset, constitutes the premonitory diarrhoea, and later the dejections of cholera. As long as the absorbing surface of the canal is extensive enough to absorb as much fluid as is transuded by the morbid surface, the blood is not deprived of its natural quantum of water. But if the transuding surface has increased, and its action overpowers that of the absorbing surface, the balance is lost, and cholera is the consequence, death being more and more likely as the size of the transuding surface increases and the extent of the absorbing surface diminishes. The blood becomes gradually more viscid, and when it can circulate no more, death of necessity ensues.

Hence Prof. Pacini formulates a law to which he ascribes mathematical accuracy, and which has been, says the author, highly appreciated in the "Report presented to 